\title{
Synthesis and biological evaluation of Piroxicam derivative as a lead chelator
}

https://doi.org/10.1515/mgmc-2019-0008

Received June 18, 2018; accepted January 26, 2019.

\begin{abstract}
Lead as a potent environmental and occupational pollutant, exerts its toxic effect mainly through oxidative stress induction. Currently, chelation therapy is the only medical management of metal intoxications in clinic, but its administration is associated with various side effects as well. In this study the protective effect of synthetized Piroxicam derivative was evaluated against lead toxicity in vitro. First the chelating activity of Piroxicam derivative was studied through Jobs method and ${ }^{13} \mathrm{C}\left\{{ }^{1} \mathrm{H}\right\}$ NMR spectroscopy. Then the cytoprotective effect of Piroxicam derivative (10, 20, 50, 100 and $200 \mu \mathrm{g} / \mathrm{mL})$ was evaluated and compared with that of EDTA $(30 \mu \mathrm{g} / \mathrm{mL})$ in the presence of lead nitrate $(30 \mu \mathrm{g} / \mathrm{mL})$. The EC50 value of Piroxicam derivative was calculated as well. Finally, the chelation efficacy and antioxidant effects of Piroxicam derivative in EC50 and 2EC50 values was assessed and compared with that of EDTA. Results showed that Piroxicam derivative chelates lead ion as much as EDTA. Moreover, Piroxicam derivative prevented lead-induced cells death more effectively than EDTA which is may due to its potent innate antioxidant activity. In conclusion, the synthetized Piroxicam derivative with possessing potent chelating activity as well as potent antioxidant activity, could be considered as potential drug target in management of toxic metals poisoning.
\end{abstract}

\footnotetext{
* Corresponding author: Alireza Golaghaei, Department of Pharmacology and Toxicology, School of Medicine, AJA University of Medical Sciences, Tehran, Iran, e-mail: Golaghaei.md@gmail.com. Sayed Masoud Hosseini, Department of Pharmacology and Toxicology, School of Medicine, AJA University of Medical Sciences, Tehran, Iran.

Ali Imani, Department of Medicinal Chemistry, School of Pharmacy, Shahid Beheshti University of Medical Sciences, Tehran, Iran. Milad Rahimzadegan and Saeid Mohammadi, Department of Pharmacology and Toxicology, School of Pharmacy, Tehran University of Medical Sciences, Tehran, Iran.
}

Keywords: piroxicam derivative; chelator; toxic metal; antioxidant

\section{Introduction}

Lead $(\mathrm{Pb})$ is a toxic heavy metal, which has many industrial applications e.g. in batteries, cable sheaths, machinery manufacturing, shipbuilding, light industry, ammunition and other industries (Kennedy and Pennington, 2008). At yearend 2017, total secondary refined lead production was 1,010,000 t, moreover total secondary refined lead production in December 2017 was 84,300 t, which was 3\% more than that in December 2016 (Greenberg et al., 2016). Thus widely lead distribution in the environment is expected. Lead exposure could occur via inhaled air, dust, food, or drinking water (White et al., 2007). Lead poisoning usually occur chronically which can affect neurological, hematological, cardiovascular, gastrointestinal, and renal systems (Pfadenhauer et al., 2016). Oxidative stress is common mechanism between toxic metals and almost all of them caused oxidative damage, so that it is considered as primary mechanism in pathogenesis of these agents. There are two independent mechanisms by which lead exerts toxic effects in living organism: (1) Direct generation of reactive oxygen species (ROS) like as $\mathrm{O}_{2}^{\circ}, \mathrm{H}_{2} \mathrm{O}_{2}$, and hydroperoxides, (2) Depletion of antioxidants capacity in cells. Delta-aminolevulinic acid dehydratase (ALAD) and glutathione reductase (GR) are two enzymes inhibited by lead. ALAD inhibition results in delta-ALAD elevation which in turn enhances the formation of ROS. GR is an enzyme responsible in reduction of oxidized glutathione (GSSG) and formation of reduced glutathione (GSH). GSH is a member of antioxidant defense system in cells. Thus GR inhibition by lead results in GSH level reduction and finally antioxidant defense system dysfunction (Ahamed et al., 2005; Sugawara et al., 1991). These together cause an imbalance between oxidative and antioxidative systems of cells which results in over production of oxidative-free radicals and associated reactive oxygen species. Alteration of cellular proteins and lipids structure and function 
is the main consequence of excessive ROS formation, leading to cellular dysfunction in energy metabolism, cell signaling, cell cycle control, and overall biological activity dysfunction which ends up in cellular death (Newsholme et al., 2016). Highly reactive species produced in oxidative stress can attack essential biomolecules like as lipids, proteins, nucleic acids, and even cell structures, followed by oxidative damages and many pathological processes (Van Antwerpen and Neve, 2004). Moreover, some other studies have shown that lead exposure result in glutathione level decrease and malondialdehyde (MDA) levels increase as a lipid peroxidation biomarker (Patrick, 2006).

The ideal medical management of metal intoxications is chelation therapy (Flora and Pachauri 2010), however current chelating agents have various side effects which limit their extensive clinical use (Wang et al., 2016). So there is essential need to synthesis new chelator agent with high efficacy and low side effect.

Nonsteroidal anti-inflammatory drug (NSAIDs) are a drug class that reduce pain, decrease fever, prevent blood clots and, in higher doses, decrease inflammation. Piroxicam (Pir), as a potent NSAIDs, can forms stable complex with metals like as $\mathrm{Fe}(\mathrm{II}), \mathrm{Co}(\mathrm{II}), \mathrm{Ni}(\mathrm{II}), \mathrm{Cu}(\mathrm{II})$ and Zn(II) (Gehad and Nadia, 2004). Furthermore, antiinflammatory and antioxidant action of NSAIDs was approved in previous studies (Petersen et al., 2008). Reactive oxygen species production typically increased during inflammatory process and it was shown that some of anti-inflammatory drug, like as NSAIDs, have potential to interact with reactive species and therefor prevent oxidative damage. Previous studies showed that some NSAIDs have potency to scavenge reactive oxygen species and inhibit intracellular oxidase activity (MouithysMickalad et al., 2000). It was shown that NSAIDs, especially oxicam compound, are reactive against ROS. It was well documented that oxicam family of NSAIDs have the scavenging capacity of hydroxyl radical $(\mathrm{OH})$, superoxide anion $\left(\mathrm{O}_{2}^{-}\right)$, hypochlorous acid $(\mathrm{HOCl})$ and hydrogen peroxide $\left(\mathrm{H}_{2} \mathrm{O}_{2}\right)$. Structure/scavenging activity relationships derived from $\mathrm{H}-\mathrm{NMR}$ and C-NMR associated with mass spectroscopy revealed that oxidation of the C-3 carbon of the enolic functional group in oxicam family is key mechanism in antioxidative activity of these agents (Van Antwerpen et al., 2004). Although studies demonstrate that oxicam family of NSAIDs exert a significant scavengering activity and antioxidant effect, they remain poorer scavengers as compared to thiolcontaining molecules (Van Antwerpen and Neve, 2004). Moreover, studies revealed that antilipoperoxidation activity of oxicams is due to their scavenging properties and their capacity to change membrane fluidity (Lúcio et al., 2007). Thus, pharmacomodulation of antiinflammatory drugs is of interest in order to improve their interactions with reactive oxygen species.

In this study the chelating activity of Pir derivative (ethyl 1,2-benzothiazoline-3-(2H)-one-2-acetate 1,1-dioxide) (Figure 1), was evaluated in vitro under lead exposure taking EDTA as a positive control, since its chelating activity has already been proven in previous studies. Antioxidant activity of Pir derivative also was investigated through malondialdehyde (MDA) and the total glutathione (GSH) content measurement. It is postulate that chelating and antioxidative activity of Piroxicam derivative make it a useful candidate in prevention and management of lead or even any other toxic metal toxicity.

\section{Results}

\subsection{Pir derivative is able to form metal complex with lead}

The chelating activity of Pir derivative for lead was evaluated using Job's method based on the changes in the UV-Vis absorption spectra due to the complex formation. The result of complexation study indicates that Pir derivative is able to form metal complex with lead and the maximum $\triangle \mathrm{A}(1.66)$ is occurred in 0.65 molar ratio (Figure 2). According to Job's plot ( $\triangle \mathrm{A}$ versus molar ratio of ligand) the stoichiometry of the complex is 2:1, in other word two molecules of Pir derivative chelate one molecule of lead ion. Furthermore, in the ${ }^{13} \mathrm{C}\left\{{ }^{1} \mathrm{H}\right\}$ NMR spectra of $\mathrm{Pb}$-Pir derivative we observed down field shifting in chemical shifts of carbonyl functional groups compared to free ligand (Figure 3).

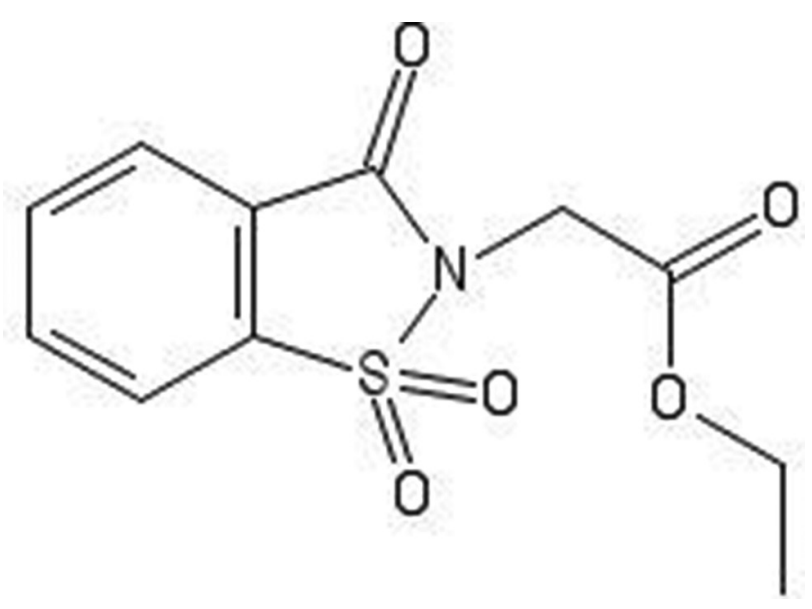

Figure 1: Pir derivative structure. 


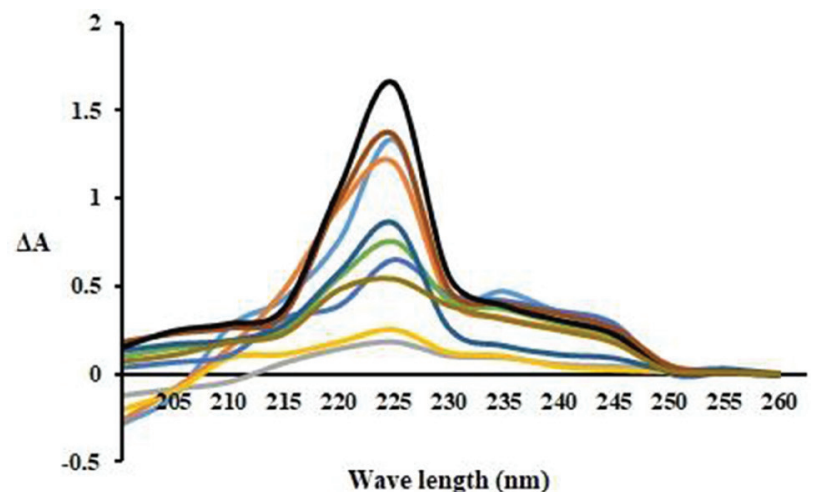

Figure 2: Changes in the UV-Vis spectra of increasing molar ration of Pir derivative in presence of lead. The black curve is the $\Delta A$ of Pir derivative with the molar ratio of 0.65 .
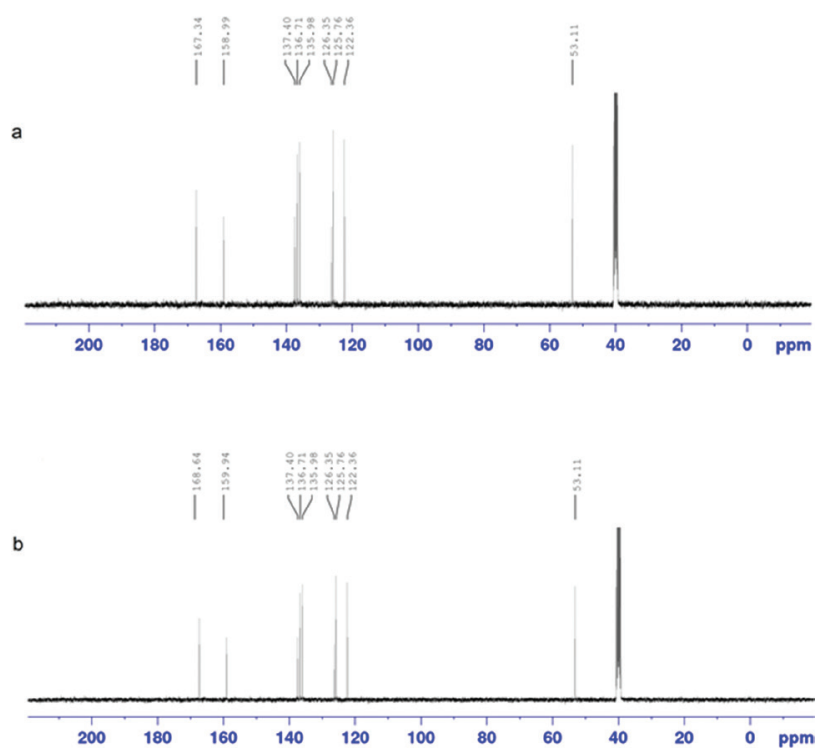

Figure 3: ${ }^{13} \mathrm{C}\left\{{ }^{1} \mathrm{H}\right\}$ NMR spectra of free Pir derivative $(\mathrm{a})$ and $\mathrm{Pb}-\mathrm{Pir}$ derivative complex (b); down field shifting in chemical shift of carbonyl groups (158.99 and 167.34 to 159.94 and 168.64 respectively). Chemical shifts of other carbon atoms within the molecule remained unchanged.

\subsection{Pir derivative increases cell viability in the setting of lead exposure}

Lead nitrate (30 $\mu \mathrm{g} / \mathrm{mL} ; 48 \mathrm{~h}$ incubation) caused significant decrease in HepG2 cells viability by about $48 \%$. The effects of different non-toxic concentrations of the Pir derivative $(10,20,50,100$ and $200 \mu \mathrm{g} / \mathrm{mL})$ or EDTA $(30 \mu \mathrm{g} / \mathrm{mL})$ on HepG2 cells viability in the setting of lead nitrate exposure were shown in Figure 4. Our results show that higher doses of Pir derivative reduced cytotoxicity of lead nitrate; the percentage of cell viability in Pir derivative treated group at the dose of 50, 100 and

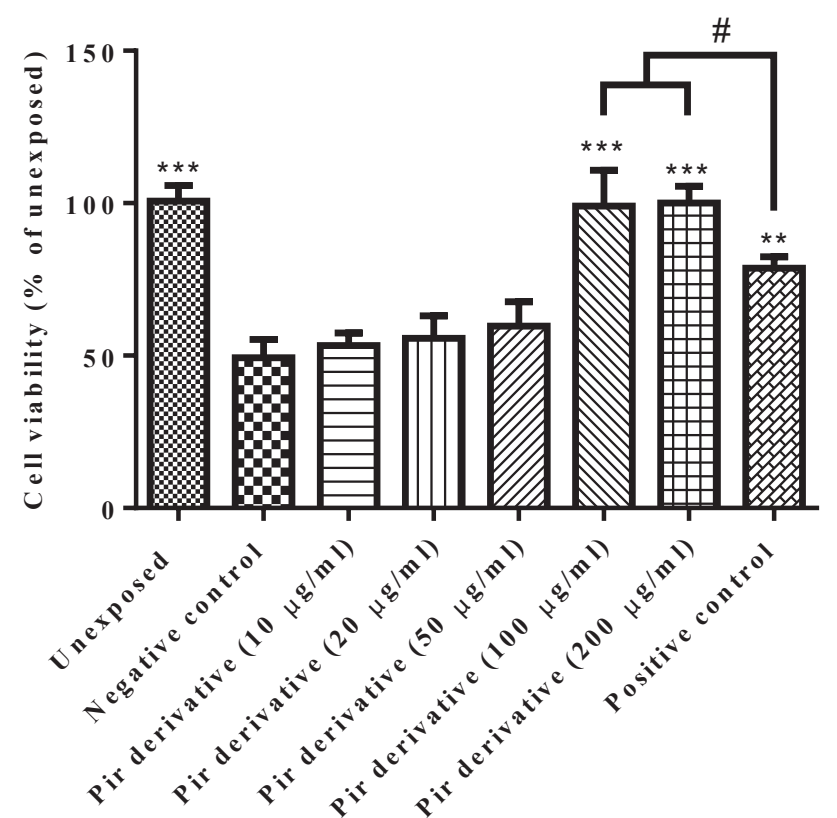

Figure 4: Cytoprotective effect of Pir derivative and EDTA against lead nitrate-induced cytotoxicity in HepG2 cells. Cells were exposed to growth medium alone (unexposed group) or growth medium containing lead nitrate ( $30 \mu \mathrm{g} / \mathrm{mL}$; negative control group) or growth medium containing $30 \mu \mathrm{g} / \mathrm{mL}$ lead nitrate plus different non-toxic concentrations of Pir derivative $(10,20,50,100$ and $200 \mu \mathrm{g} / \mathrm{mL})$ or growth medium containing $30 \mu \mathrm{g} / \mathrm{mL}$ lead nitrate plus EDTA $\left(30 \mu \mathrm{g} / \mathrm{mL}\right.$; positive control group) for $48 \mathrm{~h}$. ${ }^{*} \mathrm{p}<0.01$ and $\star \star * *<0.001$ compared with negative control group. \# $p<0.05$ compared with positive control group. Differences were compared by one-way ANOVA. Data were expressed as mean \pm SD of three identical experiments made in three replicate.

$200 \mu \mathrm{g} / \mathrm{mL}$ significantly increased, compared with untreated group (negative control group) ( $<<0.05$, $\mathrm{p}<0.001$ and $\mathrm{p}<0.001$ respectively). Pir derivative at the dose of $100 \mu \mathrm{g} / \mathrm{mL}$ resulted in the highest protective effect against lead nitrate cytotoxicity, compare with lower doses. Furthermore, there was significant difference between cytoprotective effect of Pir derivative (100 and $200 \mu \mathrm{g} / \mathrm{mL})$ and EDTA $(30 \mu \mathrm{g} / \mathrm{mL})$ against lead nitrate toxicity $(\mathrm{p}<0.05)$. Cytoprotective effect of Pir derivative at the dose of 100 and $200 \mu \mathrm{g} / \mathrm{mL}$ was comparable. Pir derivative $\mathrm{EC}_{50}$ value calculated using prism software was $72 \mu \mathrm{g} / \mathrm{mL}$ (data not shown).

\subsection{Pir derivative decreases lead uptake by HepG2 cells}

Co-treatment of lead nitrate $(30 \mu \mathrm{g} / \mathrm{mL})$ and $\mathrm{EC}_{50}$ or $2 \mathrm{EC}_{50}$ value of Pir derivative resulted in lead uptake reduction by HepG2 cells, compared with negative control group $(\mathrm{p}<0.05$ and $\mathrm{p}<0.001$ respectively). Moreover, EDTA 
$(30 \mu \mathrm{g} / \mathrm{mL})$ and Pir derivative at the dose of $2 \mathrm{EC}_{50}$ had the highest and comparable efficacy in prevention of lead uptake by HepG2 cells; lead uptake reduced by about $60 \%$ in these group (Figure 5).

\subsection{Pir derivative reduces lipid peroxidation and increases total glutathione content}

Lead nitrate $(30 \mu \mathrm{g} / \mathrm{mL})$ caused significant increase in lipid peroxidation and decrease in total glutathione content compared to unexposed cells (cells exposed to growth medium alone) $(\mathrm{p}<0.001) . \mathrm{EC}_{50}$ value of Pir derivative and $30 \mu \mathrm{g} / \mathrm{mL}$ EDTA decreased lipid peroxidation and increased total glutathione content, compared with untreated group (negative control group). The highest reduction in lipid peroxidation and increase in total glutathione content was observed in cells treated with $2 \mathrm{EC}_{50}$ value of Pir derivative (Figure 6).

\section{Discussion}

Cytotoxicity and oxidative damage induced by lead exposure was observed here in HepG2 cells. As a result

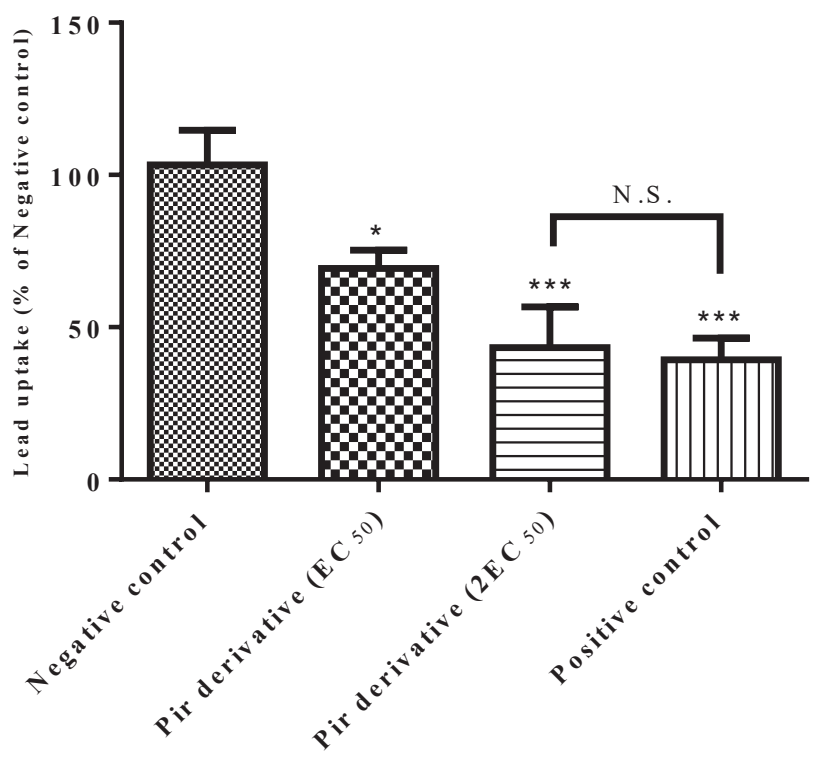

Figure 5: Lead uptake percentage in Pir derivative and EDTA treated group in ratio to negative control group. HepG 2 cells were exposed to growth medium containing lead nitrate $(30 \mu \mathrm{g} / \mathrm{mL}$; negative control group) or growth medium containing $30 \mu \mathrm{g} / \mathrm{mL}$ lead nitrate plus $\mathrm{EC}_{50}$ or $2 \mathrm{EC}_{50}$ values of Pir derivative or growth medium containing $30 \mu \mathrm{g} / \mathrm{mL}$ lead nitrate plus EDTA $(30 \mu \mathrm{g} / \mathrm{mL}$; positive control group) for $48 \mathrm{~h}$. ${ }^{\star} p<0.05$ and ${ }^{\star \star \star} * p<0.001$ compared with negative control group. Differences were compared by one-way ANOVA. Data were expressed as mean \pm SD of three identical experiments made in three replicate. N.S: Not significant. of oxidative stress induced by lead, GSH content (the index of the intracellular non-enzymatic antioxidant defenses) was decreased and MDA level (biomarker for lipid peroxidation) was increased in exposed cells. These consequences caused significant reduction of cell viability in MTT test (Figure 4). These findings were in parallel with previous reports suggesting that almost all toxic metal caused oxidative damage (Mikirova et al., 2011; Patrick, 2006). Thus, compounds with both antioxidant and chelating activity, could be effective candidate for toxic metal poisoning.

Potential activity of oxicam compounds in biomedical chemistry and their strong chelating activity for metal ions make them to be of interest in recent investigations (El-Gamel, 2009). UV-Vis and IR spectra data revealed that Pir through amide-CO and pyridine- $\mathrm{N}$, behaves as neutral bidentate ligand coordinated to the metal ions (Gehad and Nadia, 2004). Therefore, oxicam derivative through bi-functional mechanism (chelating activity along with antioxidant activity), could be a good candidate for drug targeting in the setting of heavy metal toxicity, like as lead toxicity.

In this study Pir derivative (ethyl 1,2-benzothiazoline3-(2H)-one-2-acetate 1,1-dioxide) was synthetized and its efficacy in lead chelation was assessed. Change in UV-Vis and ${ }^{13} \mathrm{C}\left\{{ }^{1} \mathrm{H}\right\}$ NMR spectra of Pir derivative in the presence of lead nitrate suggests its ability in complex formation with lead. Moreover, the maximum $\Delta \mathrm{A}$ of different molar ratio of Pir derivative in presence of lead suggests the maximum Pir derivative/lead complex formation which also provide the stoichiometric ratio. In this experiment, the maximum $\Delta \mathrm{A}$ was observed in the molar ratio of $65: 35$ (65\% Pir derivative solution and 35\% lead nitrate solution) (Figure 2) which suggests the requirement of two ligand molecules (Pir derivative) for chelating of one lead ion. Another strong evidence for chelating activity of Pir derivative was provided by ${ }^{13} \mathrm{C}\left\{{ }^{1} \mathrm{H}\right\}$ NMR experiments. Down field shifting observed in ${ }^{13} \mathrm{C}\left\{{ }^{1} \mathrm{H}\right\}$ NMR spectra is most likely due to conjugation of carbonyl groups with positively charged $\mathrm{Pb}^{2+}$. Afterward, the chelating activity of Pir derivative was compared with that of EDTA through measurement of lead uptake by HepG2 cells exposed to lead nitrate. The date revealed that Pir derivative both in $\mathrm{EC}_{50}$ and in $2 \mathrm{EC}_{50}$ values significantly reduced lead uptake percentage compared with untreated cells. $2 \mathrm{EC}_{50}$ values of Pir derivative could prevent lead uptake as much as EDTA (Figure 5). Although lead chelation activity of Pir derivative and EDTA was comparable, but surprisingly the percentage of viable cells exposed to lead in Pir derivative treated group was more than EDTA treated group (Figure 4). It assumed that such potent cytoprotective effect of Pir derivative in 

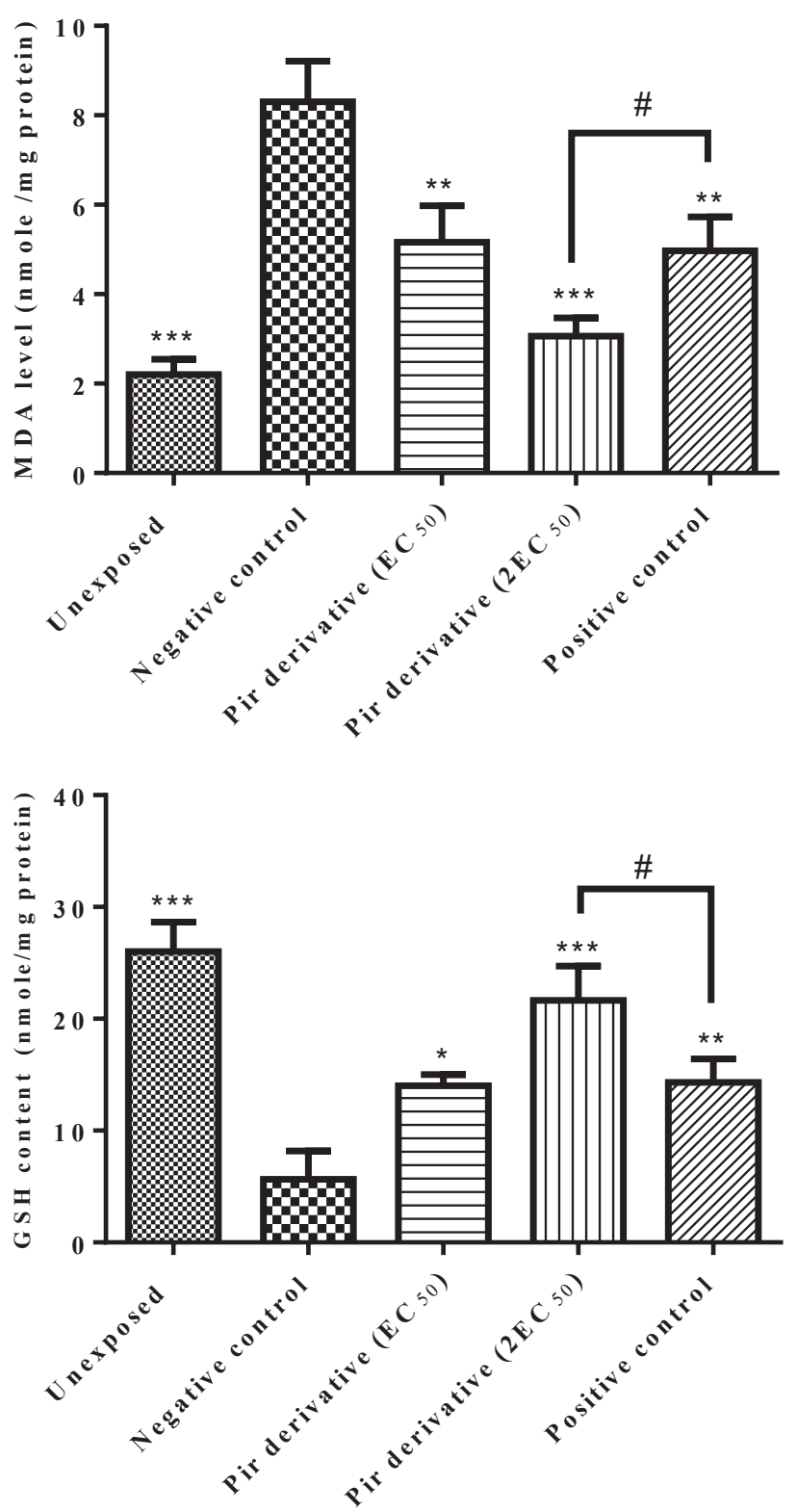

Figure 6: Lipid peroxidation (A) and GSH (B) levels change in lead nitrate exposed HepG2 cells after Pir derivative and EDTA treatment. Cells were exposed to growth medium alone (unexposed group) or growth medium containing $30 \mu \mathrm{g} / \mathrm{mL}$ lead nitrate (negative control group) or growth medium containing $30 \mu \mathrm{g} / \mathrm{mL}$ lead nitrate plus $\mathrm{EC}_{50}$ or $2 \mathrm{EC}_{50}$ values of Pir derivative or growth medium containing $30 \mu \mathrm{g} / \mathrm{mL}$ lead nitrate plus $30 \mu \mathrm{g} / \mathrm{mL}$ EDTA (positive control group) for 48 h. ${ }^{*} p<0.05,{ }^{* \star} p<0.01$ and ${ }^{* * *} p<0.001$ compared with negative control group. $\# p<0.05$ compared with positive control group. Differences were compared by one-way ANOVA. Data were expressed as mean $\pm S D$ of three identical experiments made in three replicate.

lead exposed cell is due to its potent innate antioxidant activity, compared with EDTA. For confirmation of this assumption the antioxidant activity of Pir derivative and EDTA was compared in cells exposed to lead (Figure 6). According to data, both Pir derivative and EDTA reduced lead induced oxidative damage, so that MDA levels were decreased and GSH content was increased in treated group compared with negative control group. Although EDTA showed antioxidant effect, but it was considerably less than that of $2 \mathrm{EC}_{50}$ value of Pir derivative. This could also explain the difference between $2 \mathrm{EC}_{50}$ value treated group and EDTA treated group in cell viability. In other word, although Pir derivative and EDTA have comparable chelating activity, but because of Pir derivative potent innate antioxidant activity, the cell viability in Pir derivative treated group was more compared with EDTA treated group. The relatively weak antioxidant activity of EDTA could be correlate to its lead chelating activity by which inhibits lead induced oxidative stress.

\section{Conclusion}

In conclusion, this study demonstrated that synthetized Pir derivative could effectively chelate lead ion and its chelating activity was comparable to EDTA. Moreover, cytoprotective effect of Pir derivative against lead exposure, was more than that of EDTA which probably is due to its ROS scavenging properties and also its relatively strong innate antioxidant activity. Since almost all toxic metals share the same mechanism in oxidative stress induction, synthetized Pir derivative may have protective effect against any other toxic metal poisoning.

\section{Experimental}

\section{Chemicals}

Ethyl chloroacetate, sodium saccharin, dimethylformamide, Dimethyl sulfoxide (DMSO) and Ethylenediaminetetraacetic acid (EDTA) were purchased from Merck (Germany) Chemical Company. Lead nitrate $(100 \%$ purity) was obtained from Fisher Scientific in Fair Lawn, New Jersey. Dulbeco's Modified Eagle's Medium (DMEM), fetal bovine serum (FBS), penicillin and streptomycin, MTT (3-(4, 5-dimethylthiazol-2-yl)-2, 5 diphenyltetrazolium bromide), Bradford solution, thiobarbituric acid (TBA), and 5,5'-Dithiobis (2-nitrobenzoic acid) (DTNB) were purchased from Sigma Chemical Company (St. Louis, MO, USA).

\section{Synthesis of ethyl 1,2-benzothiazoline- 3-(2H)-one-2-acetate 1,1-dioxide}

Synthesis of ethyl 1,2-benzothiazoline-3-(2H)-one-2acetate 1,1-dioxide was done according to previous reports 
(D’Ascenzio et al., 2014; Jie et al., 2014). Ethyl chloroacetate (11.9 $\mathrm{g}, 109.6 \mathrm{mmol}$ ) was added to a solution of sodium saccharin ( $14.5 \mathrm{~g}, 72 \mathrm{mmol})$ in dimethylformamide $(25 \mathrm{~mL})$. The mixture was heated at $120^{\circ} \mathrm{C}$ for $3 \mathrm{~h}$. The reaction mixture was cooled to room temperature and then poured into ice water $(50 \mathrm{~mL})$, resulting in an immediate formation of white solid, which was filtered and washed with plenty of water. The solid was dried $\left(70^{\circ} \mathrm{C}\right.$, overnight, under vacuum) to produce (2) (17.6 g, $65.6 \mathrm{mmol}, 85 \%)$ as white crystalline solid. m.p: $115-116^{\circ} \mathrm{C}$; FT-IR $(\mathrm{KBr}) v_{\max }$ : 2980, 1750, 1730, 1320, $1180 \mathrm{~cm}^{-1}$; ${ }^{1} \mathrm{H}-\mathrm{NMR}$ (400 MHz): $\left(\mathrm{CDCl}_{3}\right)$ 8: 8.38-7.90 (4H, m, aromatic), $4.60\left(2 \mathrm{H}, \mathrm{s}, \mathrm{CH}_{2}\right)$, $3.85\left(2 \mathrm{H}, \mathrm{q}, \mathrm{s}, \mathrm{CH}_{2}\right), 1.12\left(3 \mathrm{H}, \mathrm{t}, \mathrm{CH}_{3}\right) ;$ LCMS (ESI): m/z: 270 $[\mathrm{M}+\mathrm{H}], 292[\mathrm{M}+\mathrm{Na}]$.

\section{Complexation studies}

The ability of Pir derivative to chelate the lead was accomplished using the method of Job, in which the complex formation caused the UV-Vis absorption maxima intensity changes. In this method equimolar solutions of metal ion and ligand are mixed and after recording the UV spectra the difference in the maximum absorbance $(\triangle \mathrm{A})$ versus the molar ratio $(\mathrm{X})$ of the ligand is plotted; in this way the stoichiometric coefficient of the complex can be achieved. In this study, $4 \times 10^{-4} \mathrm{M}$ solution of Pir derivative in 1:5 DMSO/water and $4 \times 10^{-4} \mathrm{M}$ solution of lead nitrate in water were prepared. The solutions of Pir derivative and lead nitrate were mixed in order to obtain an increasing molar ration of Pir derivative (from 0.1 to 0.95 ) and maintaining unchanged the total concentration of Pir derivative+lead nitrate $\left(4 \times 10^{-4} \mathrm{M}\right)$. Each solution was placed in cuvette and the UV-Vis spectra were recorded (Shimadzu uv-160A) in $223 \mathrm{~nm}$ (Pir derivative maximum absorbance) using an equimolar Pir derivative solution as blank. The stoichiometry of chelation can be calculated using following equation:

$$
n=(1-X) / X
$$

where " $X$ " is the molar ratio that causes the maximum $\Delta \mathrm{A}$ and " $n$ " is the number of ligand molecules per cation present in the complex (Friggeri et al., 2015).

We also performed ${ }^{13} \mathrm{C}\left\{{ }^{1} \mathrm{H}\right\}$ NMR studies of both free Pir derivative and $\mathrm{Pb}$-Pir derivative in accordance to many similar works (Fang et al., 2014; Ye et al., 2002) on synthesis of chelating compounds. For CNMR studies of $\mathrm{Pb}$-Pir derivative we mixed lead nitrate and Pir derivative in 1:2 molar ratio. ${ }^{13} \mathrm{C}\left\{{ }^{1} \mathrm{H}\right\}$ NMR spectra were obtained on a BRUKER $400 \mathrm{MHz}$ spectrometer. We used DMSO-d6 as solvent in our experiments. Chemical shifts for ${ }^{13} \mathrm{C}\left\{{ }^{1} \mathrm{H}\right\}$ NMR spectra were referenced to the instrument's locked values for the solvent DMSO-d6 at $39.52 \mathrm{ppm}$.

\section{Cell culture}

The human hepatocellular carcinoma (HepG2) cell line was purchased from National Center for Cell Sciences, Pasteur Institute of Iran. In the laboratory, HepG2 cells stored in liquid nitrogen. They were thawed by immersion of their vials in a water bath at $30^{\circ} \mathrm{C}$ for $4 \mathrm{~min}$. Afterward, the cells were transferred to a tissue culture flask $\left(75 \mathrm{~cm}^{2}\right)$, diluted with DMEM containing $10 \%(\mathrm{v} / \mathrm{v})$ fetal bovine serum (FBS) and $1 \%(\mathrm{v} / \mathrm{v})$ streptomycin and penicillin. Cells were maintained in $5 \% \mathrm{CO} 2$ incubator at $37^{\circ} \mathrm{C}$. The culture medium was renovated with fresh medium twice weekly. Cells were detached by trypsinization when they reached $75-85 \%$ confluency. Prior to the beginning of any biologic assay, plates were changed to FBS-free medium. Because serum might interfere with the results of assays. Furthermore, it was shown that HepG2 cells have fairly good growth in FBS-free DMEM (Alía et al., 2006).

\section{Measurement of cell viability}

For cell viability measurement, $200 \mu \mathrm{l}$ growth medium containing $1 \times 10^{4}$ cells were seeded in each well of 96-well plates, followed by an overnight incubation. After determination of non-toxic concentrations of Pir derivative, cells were exposed to growth medium alone (as unexposed group) or growth medium containing lead nitrate $(30 \mu \mathrm{g} / \mathrm{mL}$ (Yedjou and Tchounwou, 2007); as negative control group) or growth medium containing $30 \mu \mathrm{g} / \mathrm{mL}$ lead nitrate plus different nontoxic concentrations of Pir derivative (10, 20, 50, 100 and $200 \mu \mathrm{g} / \mathrm{mL}$; as treatment group) or growth medium containing $30 \mu \mathrm{g} / \mathrm{mL}$ lead nitrate plus EDTA $\left(100 \mu \mathrm{mol} \mathrm{l}^{-1} \approx\right.$ $30 \mu \mathrm{g} / \mathrm{mL}$ (Fischer et al., 1998); as positive control group) for $48 \mathrm{~h}$ (three replicates per experimental group). Cell viability was determined using the MTT assay (Mosmann, 1983; Tchounwou et al., 2000). Briefly, supernatants were aspirated out and MTT solution was added to each well and incubated for $3 \mathrm{~h}$ at $37^{\circ} \mathrm{C}$. Then, the supernatant was replaced by isopropanol to dissolve the formazan crystals. One hour after incubation with isopropanol, the formazan dye was quantitated at $570 \mathrm{~nm}$ using an ELISA reader (Spectra Rainbow, Thermo, TECAN). The $\mathrm{EC}_{50}$ value of Pir derivative was determined using GraphPad Prism v. 6.07 software. 


\section{Lead uptake experiments}

Cells were exposed to $30 \mu \mathrm{g} / \mathrm{mL}$ lead nitrate alone or $30 \mu \mathrm{g} / \mathrm{mL}$ lead nitrate plus $\mathrm{EC}_{50}$ or $2 \mathrm{EC}_{50}$ value of Pir derivative or $30 \mu \mathrm{g} / \mathrm{mL}$ lead nitrate plus $30 \mu \mathrm{g} / \mathrm{mL}$ EDTA. Following $48 \mathrm{~h}$ incubation at $37^{\circ} \mathrm{C}$, the cells were washed four times with PBS, detached by trypsinization and aliquots counted. After sample preparation (Mikirova et al., 2011; Tiffany-Castiglioni et al., 1996), lead contents of cell were determined by atomic absorption spectrometry (AAS; PERKIN-ELMER, 1100B). The lead content of the samples was normalized with respect to cell numbers.

\section{Lipid peroxidation assessment and total glutathione content measurement}

Cells were exposed to growth medium alone (unexposed group) or growth medium containing $30 \mu \mathrm{g} / \mathrm{mL}$ lead nitrate (negative control group) or growth medium containing $30 \mu \mathrm{g} / \mathrm{mL}$ lead nitrate plus $\mathrm{EC}_{50}$ or $2 \mathrm{EC}_{50}$ values of Pir derivative (treatment group) or growth medium containing $30 \mu \mathrm{g} / \mathrm{mL}$ lead nitrate plus $30 \mu \mathrm{g} / \mathrm{mL}$ EDTA (positive control group). Following $48 \mathrm{~h}$ incubation at $37^{\circ} \mathrm{C}$, cell culture media were centrifuged at $1300 \times \mathrm{g}$ to separate any sedimentation. The cell pellets were suspended in $400 \mu$ l chilled lysis buffer containing $250 \mathrm{mM}$ sucrose, $12 \mathrm{mM}$ Tris-HCl, 0.1\% Triton X-100, pH 7.4, 5 mM PMSF and homogenized. The lysates were centrifuged at $12000 \times \mathrm{g}$ for $10 \mathrm{~min}$ at $4^{\circ} \mathrm{C}$ and the cell extracts (supernatants) were used for lipid peroxidation assessment and total glutathione content measurement. Protein concentration in the cell extracts was determined by Bradford assay (Nowrouzi et al., 2010). Lipid peroxidation was estimated through malondialdehyde (MDA) measurement using the method of Ohkawa et al. (Ohkawa et al., 1979), and the total GSH content was determined according to Ellman's method (Ellman, 1959).

\section{Statistics}

Data were presented as mean \pm standard deviation (SD). One-way analysis of variance (one-way ANOVA) followed by post hoc Tukey test was used to analyze the data. Differences were considered significant if $P$ values were $<0.05$. Analyses were done using GraphPad Prism v. 6.07 software. For analysis of data at least three independent experiments were used.

Acknowledgement: The study conducted under supervision of Dr. Alireza golaghaei at Department of
Pharmacology and Toxicology, School of Medicine, AJA University of Medical Sciences, Tehran, Iran.

Conflict of interest: The authors declare no conflict of interest.

\section{References}

Ahamed M., Verma S., Kumar A., Siddiqui M., Environmental exposure to lead and its correlation with biochemical indices in children. Sci. Total Environ., 2005, 346, 48-55.

Alía M., Ramos S., Mateos R., Granado-Serrano A.B., Bravo L., Goya L., Quercetin protects human hepatoma HepG2 against oxidative stress induced by tert-butyl hydroperoxide. Toxicol. Appl. Pharmacol., 2006, 212, 110-118.

D’Ascenzio M., Carradori S., De Monte C., Secci D., Ceruso M., Supuran C.T., Design, synthesis and evaluation of N-substituted saccharin derivatives as selective inhibitors of tumor-associated carbonic anhydrase XII. Biorg. Med. Chem., 2014, 22, 1821-1831.

El-Gamel N.E., The interactions of metal ions with nonsteroidal anti-inflammatory drugs (oxicams). J. Coord. Chem., 2009, 62, 2239-2260.

Ellman G.L., Tissue sulfhydryl groups. Arch. Biochem. Biophys., 1959, 82, 70-77.

Fang J., Wei X., Sapp J.B., Deng Y., Novel platinum (II) complexes containing diaminocyclohexane and thiourea derivative ligands: Synthesis and X-ray crystal structure of (trans-1, 2-diaminocyclohexane) dithioureaplatinum (II) nitrate monohydrate. Inorg. Chim. Acta, 2014, 411, 5-10.

Fischer A.B., Hess C., Neubauer T., Eikmann T., Testing of chelating agents and vitamins against lead toxicity using mammalian cell cultures. Analyst, 1998, 123, 55-58.

Flora S.J., Pachauri V., Chelation in metal intoxication. Int. J. Environ. Res. Public Health, 2010, 7, 2745-2788.

Friggeri L., De Vita D., Pandolfi F., Tortorella S., Costi R., Di Santo R., et al., Design, synthesis and evaluation of 3, 4-dihydroxybenzoic acid derivatives as antioxidants, bio-metal chelating agents and acetylcholinesterase inhibitors. J. Enzyme Inhib. Med. Chem., 2015, 30, 166-172.

Gehad G.M., Nadia E.E.-G., Preparation and spectroscopic characterisation of metal complexes of piroxicam. Vib. Spectrosc., 2004, 36, 97-104.

Greenberg N., Frimer R., Meyer R., Derazne E., Chodick G., Lead exposure in military outdoor firing ranges. Mil. Med., 2016, 181, 1121-1126.

Jie W., Qinlong X., Jiaming L., Enli Z., Minhua H., Wenfeng Y., et al., Design, Synthesis and Biological Activity of 1, 2-Benzothiazine Derivatives as Potential Anticancer Agents. Chin. J. Org. Chem., 2014, 34, 2040-2046.

Kennedy P., Pennington S., Urban sources of copper, lead and zinc. Prepared by Organization for Auckland Regional Council. Auckland Regional Council Technical Report, 2008.

Lúcio M., Ferreira H., Lima J.L., Reis S., Use of liposomes to evaluate the role of membrane interactions on antioxidant activity. Anal. Chim. Acta, 2007, 597, 163-170.

Mikirova N., Casciari J., Hunninghake R., Efficacy of oral DMSA and intravenous EDTA in chelation of toxic metals and improvement of the number of stem/progenitor cells in circulation. Transl. Biomed., 2011, 2, 1-8. 
Mosmann T., Rapid colorimetric assay for cellular growth and survival: application to proliferation and cytotoxicity assays. J. Immunol. Methods, 1983, 65, 55-63.

Mouithys-Mickalad A.M., Zheng S.-X., Deby-Dupont G.P., Deby C.M., Lamy M.M., Reginster J.-Y.Y., et al., In vitro study of the antioxidant properties of non steroidal anti-inflammatory drugs by chemiluminescence and electron spin resonance (ESR). Free Radic. Res., 2000, 33, 607-621.

Newsholme P., Cruzat V.F., Keane K.N., Carlessi R., de Bittencourt P.I.H., Molecular mechanisms of ROS production and oxidative stress in diabetes. Biochem. J., 2016, 473, 4527-4550.

Nowrouzi A., Meghrazi K., Golmohammadi T., Golestani A., Ahmadian S., Shafiezadeh M., et al., Cytotoxicity of subtoxic AgNP in human hepatoma cell line (HepG2) after long-term exposure. Iran. Biomed. J., 2010, 14, 23-32.

Ohkawa H., Ohishi N., Yagi K., Assay for lipid peroxides in animal tissues by thiobarbituric acid reaction. Anal. Biochem., 1979, 95, 351-358.

Patrick L., Lead toxicity part II: the role of free radical damage and the use of antioxidants in the pathology and treatment of lead toxicity. Altern. Med. Rev., 2006, 11, 114.

Petersen A., Carlsson T., Karlsson J.-O., Zetterberg M., Intracellular effects of NSAIDs/ASA in oxidatively stressed human lens epithelial cells in culture. Ophthalmic Res., 2008, 40, 77-85.

Pfadenhauer L.M., Burns J., Rohwer A., Rehfuess E.A., Effectiveness of interventions to reduce exposure to lead through consumer products and drinking water: a systematic review. Environ. Res., 2016, 147, 525-536.

Sugawara E., Nakamura K., Miyake T., Fukumura A., Seki Y., Lipid peroxidation and concentration of glutathione in erythrocytes from workers exposed to lead. Occup. Environ. Med., 1991, 48, 239-242.
Tchounwou P., Wilson B., Schneider J., Ishaque A., Cytogenetic assessment of arsenic trioxide toxicity in the Mutatox, Ames II, and CAT-TOX (L) assays. In: Metal Ions in Biology and Medicine International Symposium. John Libbey, 1998.

Tiffany-Castiglioni E., Legare M.E., Schneider L.A., Harris E.D., Barhoumi R., Zmudzki J., et al., Heavy metal effects on glia. Methods. Neurosci., 1996, 30, 135-166.

Van Antwerpen P., Dubois J., Gelbcke M., Neve J., The reactions of oxicam and sulfoanilide non steroidal anti-inflammatory drugs with hypochlorous acid: determination of the rate constants with an assay based on the competition with para-aminobenzoic acid chlorination and identification of some oxidation products. Free Radic. Res., 2004, 38, 251-258.

Van Antwerpen P., Neve J., In vitro comparative assessment of the scavenging activity against three reactive oxygen species of non-steroidal anti-inflammatory drugs from the oxicam and sulfoanilide families. Eur. J. Pharmacol., 2004, 496, 55-61.

Wang Z., Yan Y., Yu X., Li W., Li B., Qin C., Protective effects of chitosan and its water-soluble derivatives against lead-induced oxidative stress in mice. Int. J. Biol. Macromol., 2016, 83, 442-449.

White L., Cory-Slechta D., Gilbert M., Tiffany-Castiglioni E., Zawia N., Virgolini M., et al., New and evolving concepts in the neurotoxicology of lead. Toxicol. Appl. Pharmacol., 2007, 225, 1-27.

Ye B.-H., Li X.-Y., Williams I.D., Chen X.-M., Synthesis and structural characterization of di-and tetranuclear zinc complexes with phenolate and carboxylate bridges. Correlations between ${ }^{13}$ CNMR chemical shifts and carboxylate binding modes. Inorg. Chem., 2002, 41, 6426-6431.

Yedjou C.G., Tchounwou P.B., N-acetyl-l-cysteine affords protection against lead-induced cytotoxicity and oxidative stress in human liver carcinoma (HepG2) cells. Int. J. Environ. Res. Public Health, 2007, 4, 132-137. 